\title{
DESLIZANDO SENTIDOS: UMA ANÁLISE DAS INTERPRETAÇÕES DE LEITORES CHINESES PARA UMA PEÇA PUBLICITÁRIA VEICULADA NA MÍDIA IMPRESSA LATINO- AMERICANA*
}

\author{
He Shan ${ }^{* *}$ \\ Ricardo Moutinho ${ }^{\star * *}$ \\ University of Macau, China \\ Faculty of Arts and Humanities \\ Department of Portuguese \\ Macau, China
}

\begin{abstract}
Resumo: Neste trabalho, investigamos os efeitos produzidos por sujeitos chineses a partir da leitura de uma peça publicitária da marca Colgate, divulgada na mídia impressa sulamericana, vencedora do Prêmio de Prata no Festival de Cannes de 2011. Segundo a perspectiva discursiva, consideramos o texto um conjunto de sentidos, ligado à sua exterioridade, isto é, o interdiscurso. Por isso, o texto não é uma unidade fechada em si, nem algo que tem um sentido evidente e pronto para ser capturado pelo sujeito-leitor. Assim, distintas leituras a partir de um mesmo texto são possíveis. Para sustentar esta hipótese, realizamos uma série de entrevistas com tópicos semiestruturados com quatro participantes e analisamos o corpus constituído por suas leituras relacionadas a essa peça, identificando as semelhanças e diferenças entre elas. Os resultados mostram que os participantes produziram leituras diversificadas, que os identificam não só como sujeitos pertencentes a uma cultura diferente daquela na qual a peça foi inicialmente divulgada, mas como sujeitos diferentes entre si, uma vez que a interpretação de um texto não é linear, mas marcada pelo complexo jogo interdiscursivo.
\end{abstract}

Palavras-chave: Leitura. Peça publicitária. Participantes chineses.

1 INTRODUÇÃO

A leitura ocupa diversos espaços em nossa vida cotidiana, e a sua prática é inseparável para a aquisição e construção de conhecimentos. No processo de leitura, produzimos significados, identificamo-nos como sujeitos e encontramo-nos com o outro (o autor) em uma complexa relação de aproximação e afastamento, chamando outras vozes (discursos) para dialogar com o texto lido, desencadeando uma outra (e mais complexa) relação entre autor, leitor e suas memórias discursivas. A esta relação, damos o nome de relação dialógica. É no espaço dialógico que construímos significados para aquilo que lemos, pois é nele que associamos, comparamos e debatemos os sentidos compartilhados pelo autor.

\footnotetext{
* Este trabalho obteve o apoio financeiro da University of Macau Research and Development Administration Office (Projeto N. SRG2014-00010-FAH).

*** Mestre em Linguística pela Universidade de Macau. E-mail: xana_he@ @otmail.com

*** PhD em Linguística. E-mail: moutinho@umac.mo
} 
Assim, podemos ter uma ideia do importante papel que a leitura desempenha em nosso aprendizado e em nossa vida. Mas como acontece o processo de leitura? Quais são os recursos que mobilizamos ao lermos um texto? Como a leitura é uma das bases para a aquisição de conhecimento, se quisermos melhorar a eficácia do nosso exercício de ensinar e aprender, é preciso explorarmos mais este tema.

Para iniciar, é necessário explicarmos a diferença entre dois fundamentos importantes que norteiam o nosso processo de leitura como interpretação e construção de sentidos: a intertextualidade e a interdiscursividade, o que fazemos seguindo inicialmente a linha exposta por Fiorin (2006), que, embora reconhecendo que esses termos não ocorrem como tais na obra de Bakhtin, assume que as concepções lá estão sob diversos nomes (polifonia, heterogeneidade, dialogismo). Segundo Bakhtin (2003), o sentido de um texto nunca pode ser pré-definido pelo seu autor, pois o sentido é o resultado de uma relação dialógica entre aquilo que é dito e o que já foi dito. Por isso, o leitor não lê apenas palavras, mas constrói sentidos para o que lê em um processo que envolve o que está na superfície textual e o que é ativado em sua memória discursiva. Isso se dá de duas formas. Uma é quando o leitor, ao produzir um enunciado para aquilo que lê, faz associações (dentro da própria materialidade textual que produz) entre um discurso e outro. A isso damos o nome de intertextualidade. Um exemplo seria quando alguém, ao ler uma notícia de jornal, relata o que leu para outra pessoa, mencionando trechos do texto lido. Ao utilizar esses trechos, o leitor deixa marcada a relação discursiva entre a fala que produziu e o texto que leu. A relação dialógica está, portanto, manifestada em texto.

Porém, há momentos em que a relação dialógica não se manifesta em texto. Ela fica circunscrita no processo de interdependência de sentido (BAKHTIN, 2003), no imaginário social. A esse processo damos o nome de interdiscursividade. Supomos que um leitor que compartilha de ideais socialistas leia um texto em que o autor defende a política monetária internacional. Se o leitor, por exemplo, criticar o posicionamento tomado pelo autor do texto, ele poderá fazê-lo com base na ideologia socialista, mas não necessariamente usará trechos do texto que leu ou de textos de cunho socialista que leu ou ouviu para fazer a sua crítica. Porém, mesmo assim, poderemos notar, no discurso produzido pelo leitor, certos confrontos ideológicos em relação ao que o autor do texto expôs. Isto é, embora a relação dialógica não esteja manifestada na fala do leitor (ou seja, no texto que ele produziu), ela está presente no seu discurso.

De maneira mais simples, conforme defende Fiorin (2006, p. 181), "isso significa que a intertextualidade pressupõe sempre uma interdiscursividade, mas que o contrário não é verdadeiro". A intertextualidade, portanto, é apenas identificada quando podemos observar a relação discursiva na materialidade linguística, ou seja, na superfície textual. Do contrário, essa relação será observada por meio da postura ideológica, marcada no interdiscurso.

Independentemente da forma com que se dá a relação dialógica entre discursos, a área da Análise do Discurso (AD) de linha francesa defende que é o momento históricosocial que determina a formulação dos sentidos (CORACINI, 1995).

Em AD considera-se que o leitor não lê o mesmo texto da mesma maneira em diferentes momentos e em condições distintas de produção de leitura, e o mesmo texto é lido de maneiras diferentes em diferentes épocas, por diferentes leitores. Há uma história de leituras que afeta o texto e rege a relação dos sujeitos com o texto. Assim, foi proposto o conceito de "história das leituras", chamado de historicidade na AD. 
Antes disso, a história foi sempre colocada como algo exterior, complementar do sistema linguístico. Mas, na perspectiva da $\mathrm{AD}$, entende-se esta relação como constitutiva, implicando uma temporalidade interna do texto, e este é visto como materialidade histórica. Isso quer dizer que não se trata da historicidade refletida no texto, mas da historicidade do texto (a sua trama de sentidos). Além disso, há uma ligação entre a história externa e a historicidade do texto, ou seja, na materialidade deste está inscrita a relação com a exterioridade. Nesse sentido, o texto torna-se um objeto linguísticohistórico onde o linguístico intervém como pressuposto. $\mathrm{Na} \mathrm{AD}$, a questão da história é colocada na base da reflexão sobre a linguagem, e o seu objetivo é compreender como um texto funciona, sendo ele concebido enquanto objeto linguístico-histórico.

Em nosso trabalho, vamos aprofundar as noções de texto, leitura, discursividade, interpretação e construção de sentidos segundo teóricos da $\mathrm{AD}$, e através de entrevistas, demonstrar os efeitos de uma peça publicitária em diferentes sujeitos.

Para o objetivo mencionado, selecionamos uma peça publicitária da marca Colgate que ganhou o Prêmio de Prata (Categoria "Mídia Impressa") no Festival de Publicidade de Cannes em 2011. Nessa imagem (ver Figura I, seção 4), o fundo é todo branco, parecendo que foi pintado a giz. Na parte esquerda da imagem, uma figura negra está de pé, com a sua mão direita levantada, sendo muito destacada em contraste com o fundo branco. No canto superior direito está um tubo de creme dental com o slogan da Colgate e uma frase que sai do tubo: "A cavity ruins everything" (Uma cárie destrói tudo). Mas até aqui, algumas pessoas podem questionar: a maior parte da propaganda é imagética e a imagem não é um texto, como pode ser considerado um objeto de pesquisa para o estudo de leitura? Portanto, aqui temos que discutir o conceito de texto.

\section{QUE É TEXTO?}

Da escola primária à universidade, não conseguimos viver sem ler. Todos os dias nós obtemos uma enorme gama de informações através do processo de leitura. Como nós sabemos, a ideia de leitura é normalmente restrita ao livro, ao jornal ou às mensagens que recebemos em nossos correios eletrônicos. Leem-se palavras, e nada mais, diz o senso comum. As ciganas, contudo, dizem ler a mão humana, e os críticos afirmam ler um filme. O fato é que, quando se escapa dos limites do texto escrito, o ser humano não deixa necessariamente de ler. Ler o mapa astral, o teatro, a vida, tudo isso forma a nossa compreensão de realidade. Embora, na acepção mais comum do termo, a leitura se processe através da língua, também é possível realizar leitura através de sinais não linguísticos. Conforme Martins (2003, p. 30) afirma, "o ato de ler se refere tanto a algo escrito quanto a outros tipos de expressão do fazer humano, caracterizando-se também como acontecimento histórico e estabelecendo uma relação igualmente histórica entre o leitor e o que é lido". Como esse ato envolve o sentido da visão, ler é, na sua essência, olhar para uma coisa e ver outra. Leffa (1996, p. 10) levantou um argumento interessante:

\footnotetext{
A leitura não se dá por acesso direto à realidade, mas por intermediação de outros elementos da realidade. Nessa triangulação da leitura o elemento intermediário funciona como um espelho; mostra um segmento do mundo que normalmente nada tem a ver com sua própria consistência física.
} 
Portanto, ler significa reconhecer o mundo através de espelhos. E nessa definição geral, ler é usar segmentos da realidade para chegar a outros segmentos. Assim, "tanto a palavra escrita como outros objetos podem ser lidos, desde que sirvam como elementos intermediários, indicadores de outros elementos" (LEFFA, 1996, p. 11). O autor defende que esse processo de triangulação, de acesso indireto à realidade, é a condição básica para que o ato da leitura ocorra. Para além disso, de acordo com a perspectiva de Bakhtin (2003, p. 307), "se entendido o texto no sentido amplo como qualquer conjunto coerente de signos, a ciência das artes (a musicologia, a teoria e a história das artes plásticas) opera com textos (obras de arte)". Portanto, não apenas os livros ou jornais, mas as imagens, os sons, os espetáculos e as obras de arte também podem ser objetos de leitura. Além disso, vale ressaltar que é através de uma dispersão de textos que se chega ao discurso (CAZARIN, 2006, p. 300). Por isso, como a própria autora observa, "ao analisar um texto, levam-se em conta não apenas os elementos linguísticos, pois o mesmo é afetado pela exterioridade que lhe é constitutiva e que, embora não transparente, se reflete na/pela materialidade da língua." (CAZARIN, 2006, p. 300).

Voltando para a peça publicitária que vamos analisar, existe uma combinação de materiais semióticos nela. Está disponível no campo visual do leitor o tubo de creme dental com o nome "Colgate" e a frase que sai deste tubo, no canto superior direito da propaganda (veja Figura 1). Por isso, o leitor tem uma imagem para associar com estas palavras e produzir um significado. Portanto, imagem e palavra, neste caso, devem ser vistos como algo complementares, que fazem parte de um mesmo jogo discursivo, pois os sujeitos combinarão esses dois recursos (língua e imagem) para produzirem sentidos. Seguindo esta lógica, podemos concluir que esta campanha publicitária trata-se de um texto.

\section{A LEITURA NA PERSPECTIVA DA AD}

A AD francesa tem sua origem nos anos 1960. Nessa altura, com o progresso da Linguística, já não apenas se considera o sentido como conteúdo, o que implica que os analistas não visam o que o texto quer dizer mas como ele funciona; e há uma mudança na percepção de leitura, que aparece não simplesmente como o ato de decodificação, mas como um processo de construção de sentidos. A AD tem como objetivo descrever o funcionamento do texto, ou seja, explicitar como um texto produz sentido. Diferenciandose da visão tradicional de leitura, a AD começa a investigar outras maneiras de ler.

\subsection{A DISCURSIVIDADE DO TEXTO}

Normalmente, tratamos o texto como algo que tem início, meio e fim. No entanto, se vemos o texto como discurso - pois existe nele um efeito discursivo entre locutores não mais será uma unidade fechada e aponta sempre para outros que o sustentam. Segundo Orlandi (1987), todo texto é heterogêneo do ponto de vista de sua constituição discursiva: ele é atravessado por diferentes discursividades, afetado por diferentes posições do sujeito, em sua relação desigual e contraditória com os sentidos, com o político, com a ideologia. E esta qualidade de heterogeneidade questiona a unicidade de todo dizer e aponta para a presença do outro no dizer daquele que aparenta "um". 
Considerar o texto como discurso implica reconhecer a sua incompletude, não porque ele é constituído pelas relações de sentidos que sempre derivam de outro e apontam para outro, mas porque pode ser efeito de diferentes naturezas de memória. A incompletude é o indício da abertura do simbólico, do movimento do sentido e do sujeito, da falha, do possível. Assim o texto vai-se abrir, enquanto objeto simbólico, para as diferentes possibilidades de leitura.

Na perspectiva do discurso, o texto não é visto como uma unidade fechada, pelo que ele é inevitavelmente ligado a outros textos, quer existentes, possíveis ou imaginários, e à sua exterioridade constitutiva, isto é, o interdiscurso. Esta é a relação de um discurso com outros discursos, é o conjunto de dizeres já ditos e esquecidos que determinam o intradiscurso.

\subsection{INTERPRETAÇÃO NA AD}

A discursividade do tex to determina a sua multidimensionalidade e a multiplicidade de sentidos. Por isso temos assumido que se considere o texto, em sua materialidade, como uma "peça" com suas articulações, todas elas relevantes para a construção dos sentidos (ORLANDI, 1998, p. 14). Então, um tex to pode ser um bólide de sentidos, sendo assim um "sítio significante", do qual derivam as interpretações. Para a AD, o texto é objeto de interpretação.

Isso significa que a compreensão é posta em questão pela $\mathrm{AD}$, pois na $\mathrm{AD}$ é impossível estabelecer um acesso direto do texto ao sentido, necessitando-se da participação do leitor para que a interpretação aconteça. E esta última fica na base da constituição do sentido. Assim como o sentido é um fenômeno aberto, pensamos que a interpretação também não se fecha.

Os sentidos não são dados, mas são construídos por sujeitos inscritos numa história. Nesse processo, a história intervém para que a língua faça sentido. Com a ambiguidade, a opacidade, a espessura material do significante, surge a necessidade de administrar a interpretação, de regular as suas possibilidades e condições. Portanto, a interpretação não é mero gesto de decodificação ou apreensão do sentido, mas também não é livre de determinações.

\subsection{A CONSTRUÇÃO DE SENTIDOS}

O texto é um objeto simbólico, e face a ele, o sujeito encontra a necessidade de produzir sentidos. Isso significa realizar gestos de interpretação neste sítio de significância. Vamos recordar o que acontece conforme os métodos convencionais. Normalmente, foi estabelecida uma relação termo-a-termo entre pensamento/linguagem/mundo que é criticamente definido por Orlandi (1992) como conteudismo. O conteudismo apresenta uma tendência que valoriza mais a superfície textual, como se a relação entre palavras e coisas fosse uma relação natural e não tivesse nada a ver com a história. Nesta perspectiva, para definir os sentidos será levantada sempre uma pergunta ingênua: o que " $x$ " quer dizer? Obviamente, o problema dessa 
prática é a de se concentrar mais no conteúdo (suposto) das palavras sem se considerar o funcionamento do discurso na produção dos sentidos. Esses pontos de vista concebem a linguagem como algo transparente e a ideologia como "ocultação". Assim, a fim de encontrar o conteúdo, é preciso descobrir os verdadeiros sentidos do discurso, que estariam escondidos.

No entanto, se não nos ativermos apenas aos conteúdos da linguagem, podemos perceber como produzimos sentidos aos textos e o papel da ideologia neste processo.

Para a $\mathrm{AD}$, não existe uma relação direta do homem com o mundo, ou da linguagem com o pensamento. Isso não significa negar a existência do real natural, mas dizer que não há acesso direto a ele, o que pode ser apreendido pelo sujeito através da interpretação. Neste sentido, interpretar não é descobrir os sentidos "já dados", mas construir sentidos. É pela interpretação que o sujeito se submete à ideologia; podemos dizer que interpretação é ideologia, o que determina o sentido.

Para Pêcheux (1990), a ideologia não seria apenas um conjunto de ideias ou a mentalidade de uma época, seria aquilo que é vivido e praticado pelos sujeitos sociais sem que se tenha plena consciência. A ideologia será então percebida como o processo de produção de um imaginário, isto é, produção de uma interpretação particular que apareceria, no entanto, como a interpretação necessária e que atribui sentidos fixos às palavras, em um contex to histórico dado (ORLANDI, 1990). Resulta neste caso na ilusão de conteúdo, com o apagamento das condições materiais, históricas, de produção. Esse apagamento, sendo possível devido à inconsciência parcial do sujeito, produz um efeito de evidência, parecendo que os sentidos são únicos, óbvios, verdadeiros e eternos. De fato, não há um sentido (conteúdo), mas só o funcionamento da linguagem. E a ideologia não é um conteúdo " $x$ " mas o mecanismo de produzi-lo. Isso quer dizer que, embora os sujeitos tenham um papel ativo durante a constituição dos sentidos, o processo escapa ao seu controle consciente e às suas intenções. O sujeito está sob o efeito do apagamento da exterioridade: daí a ilusão de que o sentido nasce ali, não tem história. Esse é um silenciamento necessário, inconsciente, constitutivo para que o sujeito estabeleça sua posição, o lugar de seu dizer possível. Assim, na ideologia não há ocultação de sentidos (conteúdos) mas apagamento do processo de sua constituição.

Pensar na produção de sentidos como um processo inconsciente de produção de interpretações do real e do próprio sujeito, determinado por condições históricas e ideológicas específicas, significa pensar que os sentidos podem mudar e as sociedades podem ser outras e que as políticas são contingentes.

$\mathrm{O}$ conhecimento acima sobre a $\mathrm{AD}$ poderá ajudar-nos a adquirir o melhor entendimento da perspectiva discursiva de leitura.

Orlandi (2005), tomando como pressuposto teórico as contribuições da análise do discurso na linha pêcheutiana, define a leitura como sendo construção do sentido, sendo essa construção determinada por fatores sócio-históricos e culturais e, principalmente, ideológicos. A autora também menciona que o texto, na perspectiva discursiva, não pode ser entendido como um "recipiente" de palavras organizadas, textualizadas, que guardam o sentido. $\mathrm{O}$ texto é concebido como algo heterogêneo que é "atravessado por diferentes formações discursivas”. A partir disso, saímos de uma visão estritamente linguística, chegando a uma possibilidade teórica que compreende a leitura como discurso; isto 
significa que ler é uma prática discursiva. $\mathrm{O}$ texto seria, nessa perspectiva, o produto do processo discursivo, uma forma convencional consensualmente reconhecida de comunicação social (ORLANDI, 2005, p. 115).

\section{METODOLOGIA E PARTICIPANTES DE PESQUISA}

Em primeiro lugar, precisamos selecionar um objeto para servir como texto, isto é, o objeto de pesquisa. De acordo com o referido na seção anterior, sabemos que o texto é uma unidade feita de som, letras, sinais diacríticos, margens, notas, imagens, sequências. Neste sentido, a imagem também pode ser vista como texto.

Escolhemos uma imagem, sendo, de fato, uma peça publicitária da marca Colgate que ganhou o Prêmio de Prata (Categoria "Mídia Impressa") no Festival de Publicidade de Cannes em 2011, exposta na Figura 1.

\section{Figura 1 - Campanha publicitária da marca Colgate}

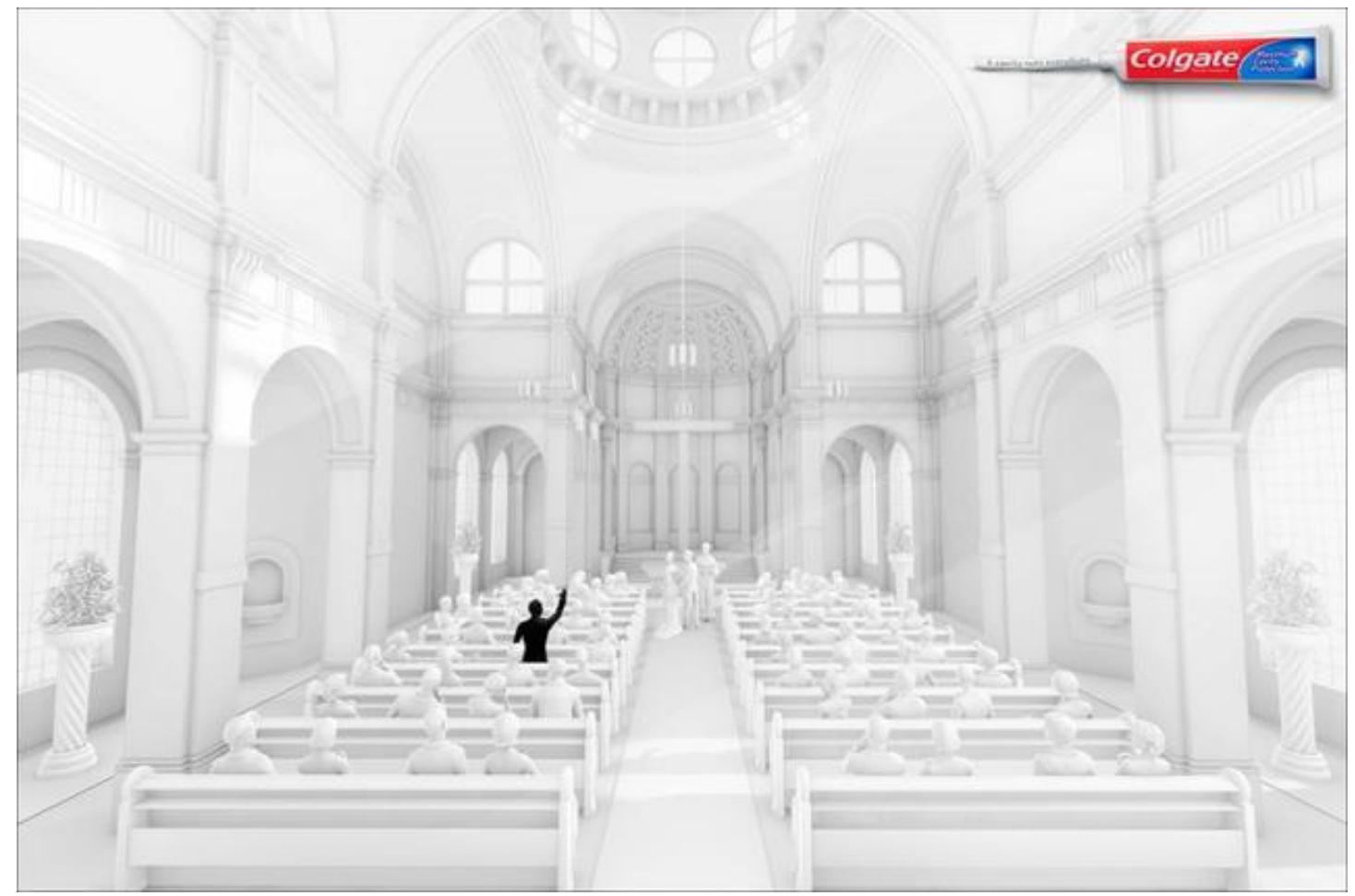

Fonte: Disponível em: <http://www.coloribus.com/adsarchive/prints/colgate-toothpaste-church-14498805/>. Acesso em 15/01/2014.

Por ter vencido esse prêmio, esta peça publicitária teve uma presença maciça na mídia. Por isso, interessava-nos saber que reações ela causava em diferentes sujeitos que não pertenciam ao espaço cultural em que a peça foi divulgada ${ }^{1}$. Como se pode observar (Figura 1), a propaganda produz o efeito de um casamento em uma igreja, evento esse presente na memória discursiva de sujeitos pertencentes a qualquer cultura ocidental.

\footnotetext{
${ }^{1}$ Esta peça publicitária foi produzida pela agência publicitária da Colgate de Santiago, no Chile, e muito divulgada na mídia impressa da América Latina. 
Porém, na China, embora o casamento religioso de cunho cristão seja cada vez mais conhecido, não são todos os sujeitos que o têm em seu arcabouço discursivo, podendo não reconhecer o evento como tal ${ }^{2}$.

Para saber quais são essas interpretações, fizemos uma série de entrevistas com tópicos semiestruturados com quatro participantes (aproximadamente 30 minutos para cada um) pedindo-lhes para produzirem interpretações após a observação da referida peça publicitária.

Foram preparadas entrevistas com tópicos semiestruturados para cada participante. Isso quer dizer que foram feitas as mesmas perguntas para cada participante, mas também foram adicionadas outras de acordo com a resposta dos sujeitos de pesquisa. Nesse processo, porém, não realizamos nenhum tipo de inferência acerca do texto publicitário lido, justamente para não induzir os participantes a uma ou a outra possibilidade de leitura. Fizemos registros escritos dos conteúdos das entrevistas, nas quais os participantes falaram em chinês. Em seguida, os dados foram traduzidos para a língua portuguesa.

Usamos as letras A, B, C e D para identificar os quatro participantes.

A seguir disponibilizamos um breve perfil de cada um.

Tabela 1 - Breve perfil dos participantes

\begin{tabular}{ccccc}
\hline Participante & Sexo & Idade & Nível Educacional & Profissão \\
\hline A & Feminino & 24 & Ensino superior incompleto & Estudante \\
B & Masculino & 23 & Ensino técnico & Funcionário de empresa \\
& & & de eletricidade \\
C & Feminino & 54 & Ensino secundário & Dona de casa \\
D & Feminino & 24 & Ensino superior (mestrado) & Estudante \\
\hline
\end{tabular}

Em nossa análise de dados, apresentaremos alguns excertos dessas entrevistas para serem discutidas. Esses excertos foram selecionados de acordo com alguns critérios, que foram elaborados com base nos temas que mais apareceram no discurso dos participantes, que foram: o lugar onde se passa a cena; os personagens; a ação que estão realizando no momento; a razão de a imagem ser quase toda branca; a representação da personagem preta; o slogan da Colgate no canto superior direito da imagem; e a mensagem publicitária que o participante produziu ao ler a propaganda.

\footnotetext{
${ }^{2}$ É importante deixar claro que ao afirmarmos a possibilidade de leitores chineses produzirem interpretações diferentes para o evento retratado na imagem, essa observação restringe-se apenas ao casamento de cunho religioso. Ou seja, não estamos afirmando que leitores ocidentais fariam uma interpretação da propaganda de modo homogêneo, livres de ressonâncias discursivas.
} 
Agora procedemos à análise do corpus, composto por textos produzidos pelos quatro participantes. Note-se que os participantes produziram seus textos originalmente em chinês, posteriormente traduzidos para português pela primeira autora deste trabalho. Como cada entrevista durou cerca de meia hora, foi registrada uma grande quantidade de informações. Por razões de limitação de espaço, apenas selecionamos excertos que consideramos discursivamente mais relevantes para serem analisados neste artigo, conforme os critérios de seleção já mencionados anteriormente.

\subsection{PARTICIPANTE A}

Primeiramente, observemos o enunciado da participante A:

Excerto 1: A minha primeira reação ao ver isto é: embora o creme dental pinte e encubra o fato de que o Papa é o manipulador da igreja, deixando tudo parecer harmonioso, escapou da tinta branca uma pessoa que se levantou corajosamente para denunciar a hipocrisia da religião, parecendo aquela criança honesta na história «A roupa nova do rei».

A participante A parece considerar que a cena foi pintada de branco pela pasta de dente. "Harmonioso" é o seu entendimento sobre este "branco", mas ela também acha que o branco tinha encoberto alguns fatos. A sua menção de «A roupa nova do rei» pertence a sua memória discursiva. Aqui a interdiscursividade aparece de forma bem explícita no enunciado desta participante. «A roupa nova do rei» é um conto de fadas de autoria do dinamarquês Hans Christian Andersen, muito conhecido na China e no mundo todo. O conto conta a seguinte história:

Há muito tempo atrás, havia um rei que gostava de vestir-se bem. Todos os dias queria usar roupas novas. Um dia, dois vigaristas, se fazendo passar por alfaiates de terras distantes, disseram ao rei que poderiam fazer uma roupa muito bonita e cara, mas que apenas as pessoas mais inteligentes e astutas poderiam vê-la. O rei, muito vaidoso, aceitou a proposta e pediu-lhes para fazer uma roupa para ele. Quando os vigaristas apresentaram ao rei essa inexistente "roupa", embora não visse nada, o rei resolveu marcar uma grande parada na cidade para que ele exibisse a sua roupa. A única pessoa a desmascarar a farsa foi uma criança: "O rei está nu!"

No fim deste conto, a cena em que a criança aponta para o rei e diz a verdade, em certa medida, seria semelhante à da imagem da propaganda, em que a pessoa preta se levanta e aponta para a pessoa no altar. A criança no conto e a personagem preta na imagem pertenceriam à minoria que é incompatível com a multidão. No conto, a criança é caracterizada por ser honesta e franca. Assim, podemos inferir que, talvez, a participante A atribuiu essas qualidades à personagem preta na imagem por apreciar o seu comportamento. Este é o efeito da interdiscursividade, que influencia a atitude e o julgamento do leitor. 
Além disso, o enunciado "a hipocrisia da religião" mostra a sua oposição em relação à religião. Isso parece estar ligado a um discurso partidário. Diferentemente do analisado acima, esse enunciado ligado à religião não traz explícita a ideia do discurso partidário, mas é ao que podemos associar em razão da posição do partido chinês3 frente às crenças e às instituições religiosas. Aqui temos um efeito da memória discursiva de A, que se manifesta de maneira parcialmente inconsciente.

Excerto 2: A igreja é um local sagrado de peregrinação. As pessoas civilizadas que tinham usado Colgate, com fala e pensamento altamente purificados, mantêm silêncio e concentramse na peregrinação. Em comparação, aquela gente que não usou o creme dental da Colgate, veste uma roupa suja, com comportamento indecente e vulgar. Fala alto na igreja, manchando a atmosfera pura e santa.

Diferentemente do enunciado anterior, nesta alegação, a participante A trata a igreja como um lugar sagrado, e considera as pessoas brancas como crentes devotos, cujos pensamentos e discursos foram "altamente purificados" por terem usado Colgate, ou podendo-se dizer, por terem fé. Por outro lado, as descrições "roupa suja", "comportamento indecente" e "vulgar" revelam sua atitude crítica em relação à personagem preta e seu desprezo pelo comportamento da mesma. Nesta opinião, a participante A parece ser uma adepta religiosa, colocando a religião numa posição sublime, e elogiando seu poder de purificar a mente.

Interessante notar que, nas duas versões de leitura produzida em dois momentos pela participante A, ela possui atitudes totalmente diferentes sobre as personagens na imagem: no primeiro momento, fez uma analogia entre a personagem preta na imagem e a criança no conto «A roupa nova do rei», parecendo apreciar a coragem e honestidade dessa personagem, enquanto que no segundo momento, acha que a mesma personagem é muito grosseira e vulgar. No seu primeiro relato, em contraste com a personagem preta, as brancas parecem banais e silenciosas, sem coragem de falar por si ou não percebendo sua situação real, enquanto que na posterior, as palavras "civilizadas", "purificados" usadas por esta participante deixam as personagens brancas com uma característica de dignidade e elegância. Além disso, no primeiro momento, a participante acusa "a hipocrisia da religião" enquanto que no segundo defende a santidade da religião. Em seu primeiro relato, o creme dental é considerado uma ferramenta que é usada para esconder alguns fatos antiéticos da igreja, enquanto que no entendimento posterior, o creme dental da Colgate torna-se uma receita para a iluminação da multidão, purificando suas palavras e ações. Assim, podemos observar que em suas duas alegações, a participante A também possui pontos de vista completamente opostos sobre a religião e o creme dental. Perante um mesmo texto, a mesma participante fez duas leituras com direções completamente distintas, em que as suas opiniões são conflituantes. Isso mostra o sujeito clivado, heterogêneo e não linear, divergindo em diferentes direções, em vez de uma única.

\footnotetext{
${ }^{3}$ Referimo-nos ao Partido Comunista Chinês, detentor de todo o poder político na República Popular da China desde 1949. Segundo a sua doutrina, que é de base ateísta, qualquer movimento ou instituição fundada em crenças é considerada um mal à sociedade.
} 
Em seguida, perguntamos à participante A por que produziu discursos diferentes nos dois momentos, e ela respondeu:

Excerto 3: A $2^{\text {a }}$ versão não é o que realmente quero expor, a personagem preta é, na verdade, o lado que quero apoiar, talvez seja porque a minha personalidade é mais afiada, penso que a verdade está nas mãos de poucos, e estes, quando aparecem, muitas vezes são rotulados como heterodoxos.

Nesta explicação, a participante A indica que prefere a sua primeira interpretação, e a partir daqui faz uma ligação a sua própria personalidade: é uma pessoa afiada (conforme sua autoavaliação). E na leitura de sua primeira interpretação, em que a personagem preta "se levantou corajosamente para denunciar a hipocrisia da religião", podemos observar a sua personalidade ideológica. Parece que a participante A usa a personagem preta para aludir a si mesma, ou seja, ela involuntariamente pensa em si mesma ao ver a personagem, pelo que, segundo a participante A, elas têm qualidades semelhantes. Vemos aqui um interessante efeito interdiscusivo, em que a participante A relaciona a imagem à sua própria personalidade. Ela acredita que nessa sociedade, a verdade está nas mãos de um pequeno grupo de pessoas, e estas nem sempre são aceites.

Em conclusão, a participante A relata:

Excerto 4: Esta é uma igreja que serve à classe dominante, o pastor está pregando com eloquência à frente. As pessoas brancas são nobres da alta sociedade que estão ouvindo o dogma monótono de forma entorpecida, enquanto que a pessoa preta representa as massas trabalhadoras ou o povo da classe baixa, que se levanta para questionar e opor-se ao papa.

A participante A trata o lugar na imagem como uma igreja, e de acordo com seu entendimento, esta serve à classe dominante em vez de servir ao público. A participante fez este julgamento sem explicar a razão. Porém, é possível estabelecermos uma associação com os fatos históricos provavelmente presentes na memória discursiva da participante em questão. Na Idade Média, a religião ocupa a posição dominante na Europa. Além disso, tão cedo como no final do Império Romano, o cristianismo era praticado pela classe dirigente. Então, podemos supor que a participante A tem algum conhecimento sobre a história da religião. As personagens brancas e a preta na imagem foram vistas por ela como pessoas de diferentes status social, representando a classe alta e a mais baixa, respectivamente. Esta é a ideia marxista da luta de classes. A diferença de classes gera a oposição e a luta. Assim, a participante A coloca as personagens de diferentes cores em posições opostas. Ao ver as pessoas brancas e pretas, ela fez uma relação correspondente com o nobre e o pobre, o que poderia ser atribuído à sua memória discursiva, ou seja, as personagens brancas e pretas naturalmente evocam as suas lembranças ou conhecimentos sobre a raça e o estado social. As palavras "dogma monótono", "de forma entorpecida" refletem o estado mental das personagens brancas: parece que elas não gostam dessas doutrinas, porém têm que as aturar. Comparando com as suas duas primeiras versões de leitura, nesta conclusão foram adicionados os elementos de luta de classes e contra a opressão. As descrições "nobres da alta sociedade", "massas trabalhadoras", "o povo da classe baixa" destacam a relação antagônica entre as personagens brancas e pretas. 
O entendimento do participante B sobre a imagem sofreu várias mudanças no processo de interpretação. Ao ver a imagem no primeiro momento, ele disse:

Excerto 5: As cores preta e branca lembram-me peças (de xadrez), de qualquer maneira, o lado preto vai perder. Por isso, a cena é um tabuleiro de xadrez?

A similaridade entre a cena representada pela imagem e a possível semelhança ao tabuleiro de xadrez fazem com que o participante B associe a peça publicitária a esse jogo. Isso vem da sua memória discursiva. Além disso, a grande disparidade no número das personagens brancas e pretas faz com que ele chegue a uma conclusão - "o lado preto vai perder", o que também é originado do seu conhecimento das regras do jogo de xadrez.

Relativamente à razão pela qual a cena é toda branca, o participante B explicou:

Excerto 6: Porque aquele que pintou esta imagem não tinha tempo suficiente para colori-la." O participante B sorri e completa: "Sou amante do desenho animado.

É interessante que o participante adota uma perspectiva que não se limita à própria imagem, mas transcende o que se encontra em seus limites. Ele não considera que "a cena toda branca" é uma maneira de refletir um determinado tema da imagem, mas trata isso apenas como uma negligência induzida pelo autor no processo da conclusão da imagem. Sobre esse entendimento, o participante B explicou que ele próprio é um fã do desenho animado. Neste sentido, a memória discursiva funciona de forma implícita, no nível do interdiscurso. Talvez o interesse pelos desenhos animados faça o participante concluir que houve supostamente um problema técnico ao colorir a imagem.

Excerto 7: Acho que a personagem preta está sendo perseguida, porque ela está a ser assistida ou assediada por outros. Com a cor diferente, ela está dessintonizada dos arredores.

De acordo com a descrição "está a ser assistida ou assediada", semelhante à da participante A, o participante B também colocou as personagens pretas e brancas em posições opostas. Porém, a diferença entre os participantes A e B é: a participante A enfatiza que a ação da personagem preta é a de se levantar corajosamente para dizer a verdade e expressar os seus pontos de vista opostos, mostrando apreciação pela sua coragem. Entretanto, no ponto de vista do participante B, a pessoa preta está "sendo perseguida", obviamente ficando numa situação vulnerável.

Em seguida, levantamos a pergunta: "Você notou o slogan da Colgate? Por que ele fica lá no canto superior direito?” O participante responde:

Excerto 8: Penso que esta investigação foi patrocinada pela Colgate. Geralmente, há empresas que fornecem fundos de atividade para as pesquisas universitárias, não é? Acho que só existe esta possibilidade. Se não, suponho que o autor desta imagem seja um fã da Colgate. Ou talvez você seja uma fã da Colgate, não consigo pensar em outras explicações. 
Mais uma vez o participante B escapa do quadro da imagem, desta vez para interpretar a figura nela e a razão de conduzirmos uma pesquisa. E mais uma vez a memória discursiva funciona de maneira implícita. Como sabemos, é um fenômeno muito comum as empresas utilizarem a sua própria marca nas obras televisivas ou em pesquisas patrocinadas. Baseado neste conhecimento, o participante julgou que os fundos para a pesquisa em curso tinham sido fornecidos pela empresa Colgate. Em seguida, o participante ainda supôs que o autor da imagem gosta da Colgate, por isso, ele coloca este slogan na imagem; ou a própria entrevistadora goste da Colgate, e assim, escolheu esta imagem com a figura da Colgate. Todas essas três respostas não têm relação direta com o conteúdo da própria imagem, mas têm ligação com a experiência de vida do participante, ou seja, é a interdiscursividade atuando no processo de construção de sentidos.

\subsection{PARTICIPANTE C}

Passamos para a interpretação da participante C. Depois de uma breve observação da imagem, a participante $C$ relatou:

Excerto 9: Aqui parece ser um teatro, e uma pessoa da plateia se levanta, com um dedo apontado para o palco, parece estar dizendo algo, mas o que seria? Todo o teatro está vazio, apenas uma pessoa está lá, o que isso significa?

A interpretação da participante $\mathrm{C}$ sobre o local da imagem é diferente daquela dos dois participantes anteriores. Esta participante é uma dona de casa, provavelmente não tendo contato com os costumes ocidentais nem estando familiarizada com uma igreja. Assim, ela trata o local na imagem como um teatro, baseado na sua memória discursiva. Talvez devido à falta de observação cuidadosa, ela não notou a diferença entre a presença de personagens brancas e pretas.

Perguntamos à participante $\mathrm{C}$ por que julgava que o local na imagem era um teatro. Ela disse:

Excerto 10: Porque há muitos assentos nas partes da frente e de trás, e na frente é como um grande palco, com pequenas portas estendidas em ambos os lados; parece haver um grande lustre no teto, portanto, aqui é como um teatro; a pessoa parece estar perguntando ou gritando algo, ele/ela quer alguma coisa ou parece manifestar algum descontentamento. Por que apenas uma pessoa está lá? Onde estão os outros? Por que é assim?

A participante descreveu detalhadamente a decoração do local, combinando com a impressão de teatro presente em sua memória discursiva. Ao relatar a sua interpretação, no entanto, a participante $\mathrm{C}$ adotou um tom incerto, demonstrando que ela ainda está confusa sobre a conotação da imagem, não formando opiniões definidas. É possível observar isso na sequência de perguntas que ela faz, por vezes à entrevistadora, por vezes a si mesma: "Por que apenas uma pessoa está lá? Onde estão os outros? Por que é assim?". 
Excerto 11: A peça acontece de dia, ou está exposta ao ar livre" ... Ah, há janelas, pode ser a luz vindo das janelas que deixa o espaço particularmente brilhante.

Quanto à cor branca da cena, a participante $\mathrm{C}$ tem uma compreensão diferente da dos dois participantes anteriores. Ela pensa que o branco é derivado do efeito da iluminação. Depois de ter notado as três personagens que estão na parte da frente, ela disse:

Excerto 12: Eles estão perto do palco e vindo para cá pelo caminho do meio? Esta pessoa com roupa preta quer dizer "olá" para eles? É este o significado?

Podemos observar quando a participante diz que as três pessoas da frente "estão vindo para cá", combinado com as ações e discursos da personagem preta, que a participante apresenta a nós um sentido mais dinâmico para a imagem. Outro ponto curioso é que a participante $\mathrm{C}$ continuou a relatar as suas observações em forma de pergunta, mostrando um certo receio em expor as suas interpretações. Preferimos não responder às suas perguntas, e continuamos a indagar: "O que está no canto superior direito?" A participante reconheceu que era uma pasta dental da marca Colgate, e disse que: "Eu usei esta; esta marca frequentemente que aparece na publicidade, os dentes ficarão muito brancos depois de usá-la."

A memória discursiva intervém de forma explícita e é manifestada no texto produzido pela participante $\mathrm{C}$, ou seja, no nível da intertextualidade. A descrição "os dentes ficarão muito brancos depois de usá-la" vem da frase de efeito utilizada pela propaganda da Colgate em comerciais televisivos na China.

Em seguida, perguntou-se por que o slogan da pasta de dentes está naquela posição. A participante respondeu, mais uma vez, em tom de pergunta:

Excerto 13: É por efeito da pasta de dentes que deixa a casa tão branca? Algumas pessoas são especialmente brancas porque elas tinham usado este creme dental, só aquela pessoa não usou. É esse o significado?

Levando em conta o padrão das propagandas de cremes dentais em geral, a participante produziu uma nova interpretação sobre a cena branca: poderia ser o efeito do creme dental. As personagens brancas representam os usuários de Colgate. Podemos ver que esta participante, como a maioria dos outros, também tem a ideia de que dente branco é dente saudável. Isto pode ser baseado no seu conhecimento anterior, sendo discurso difundido pela mídia e presente em sua memória discursiva.

Perguntamos, logo após, o que a participante achava que essa imagem podia expressar. Ela respondeu:

Excerto 14: Ele (a personagem preta) levantou-se porque todos os outros tinham usado a pasta e estão muito satisfeitos, mas só ele não usou e ficou preto; então, ele exigiu: 'por que vocês estão todos brancos, e apenas eu estou preto?! É este o sentido? 
Notamos que na interpretação desta participante, a diferença entre as personagens brancas e a personagem preta simplesmente é que as brancas tinham usado o creme dental da Colgate e a personagem preta não. Não há uma relação aparente de hostilidade entre as personagens de diferentes cores.

\begin{abstract}
Excerto 15: As pessoas da imagem estão lá para dizer a todos que a Colgate é muito importante para nossas vidas. Nesse grande teatro, muitas pessoas vão promover este creme dental, dizendo que ele é bom. Todos os assentos estavam cheios, o que indica a grande demanda deste creme dental; e muito poucas pessoas reconheceram que deve ter essa qualidade de vida, e têm de vir aqui para sentir a atmosfera, sabendo que têm que melhorar suas próprias vidas. Somente se usarem este tipo de creme dental, a qualidade de vida pode ser melhor, bem como a nossa saúde.
\end{abstract}

De acordo com este enunciado, as personagens brancas não apenas são usuárias, mas também propagandistas da marca Colgate: "muitas pessoas vão promover este creme dental, dizendo que é o mesmo é bom"; "o que indica a grande demanda deste creme dental". A participante fez tal julgamento talvez por saber que este creme dental é muito popular. Como pode ser observado, a interpretação da participante $C$ concentra-se em temas de qualidade de vida e saúde, o que reflete sua própria atenção a estas questões.

Em conclusão, podemos afirmar que a participante $\mathrm{C}$ compreendeu a imagem de forma progressiva, precisando, por vezes, do auxílio da entrevistadora para que mais perguntas fossem lançadas e, assim, mais enunciados fossem produzidos. Durante a entrevista, não paramos de lançar mão de perguntas básicas como "o que as personagens estão fazendo?" ou "quem são personagens brancas e pretas?" e cada vez a participante produzia mais ideias.

Uma característica notável da participante $\mathrm{C}$ é que, ao responder às perguntas, ela sempre usou um tom especulativo ou interrogativo, mostrando sua atitude incerta, em certa medida dando a outros uma impressão hesitante, cautelosa e de falta de confiança. Muitas vezes, depois de responder nossas perguntas, a participante, habitualmente, fazia uma pergunta esperando confirmação: “é isso que significa?", parecendo querer verificar a exatidão da resposta. Isso deixa-nos uma impressão de que ela estava fazendo uma prova oral, e cada pergunta teria uma resposta certa para ser encontrada. Isso pode estar associado a uma concepção de leitura de cunho tradicional, herdada durante a sua vida escolar. Em comparação com a autonomia dos dois primeiros participantes, no processo de produzir interpretações, a participante $\mathrm{C}$ mostrou um certo grau de dependência no início, porém, conseguiu se desvencilhar disso ao longo da entrevista, o que mostra que ela produziu um discurso mais cuidadoso sem tirar conclusões precipitadas.

Durante a entrevista, a participante $\mathrm{C}$ improvisou muitas palavras para a personagem preta, as quais não estão todas apresentadas nos excertos acima por razões de limitação de espaço, tais como "Olá, por que ainda não se puxou a cortina?! Qual será a peça?", "Por que vocês estão todos brancos, e apenas eu estou preto?!” E através dessas palavras, talvez imperceptivelmente ela expressou suas próprias dúvidas. Então, julgamos que a participante colocou-se no lugar da personagem preta, com base nos seus enunciados atribuídos a essa personagem repletos de uso da primeira pessoa do singular: "Eu recomendo vivamente usar o creme dental da Colgate"; "“'Oh, a cortina do palco não se abriu, não sei o que vai passar”; ““"Por que vocês estão todos brancos, e apenas eu estou 
preto?" (Excerto 14). Em contraste, as interpretações dos participantes A e B tendem a mostrar um estado de impasse (luta entre hipocrisia e verdade, crentes e infiéis, dois partidos a duelar no jogo de xadrez).

\title{
4.4 PARTICIPANTE D
}

A participante $\mathrm{D}$ nos perguntou se a imagem era uma propaganda da Colgate. Ela notou a funcionalidade da imagem, mas não a trata simplesmente como uma imagem qualquer. A sua interpretação:

Excerto 16: Um casal casa-se na igreja, ao qual somente aquele homem preto se opõe. Há apenas uma personagem preta na igreja, o homem é de cor preta porque ele não usou Colgate? Ele é aquele que gosta da noiva? A cena é toda branca porque foi pintada pela Colgate; apenas aquela pessoa preta é verdadeira, e os outros foram invadidos pela mercadoria de consumo.

Mesmo que tivesse notado que a imagem era a publicidade da Colgate, a participante ainda interpreta a mercadoria (representada pela Colgate) como algo negativo. A palavra "verdadeira" manifesta o seu apreço, sendo mais uma ideia positiva em relação à figura preta, mas não à propaganda. No entanto, essa ideia muda em um segundo momento. Observemos o próximo excerto.

\begin{abstract}
Excerto 17: Muito difícil... é tudo muito estranho... eu mudei de ideia: Xiao Ming interrompeu uma cerimônia de casamento de um casal realizada na igreja, porque ele não concordava com isso, não importando se ele amava aquele homem ou a mulher. Como ele tinha usado Colgate, logo que abriu a boca para falar, todas as pessoas na igreja ficaram solidificadas em pedra de cor branca; assim, ele alcançou o propósito, carregando o corpo solidificado da noiva ou do noivo e saindo.
\end{abstract}

A participante D deu à personagem preta um nome específico: Xiao Ming, sendo este um nome masculino muito comum na China. Além disso, ela é a única participante que admite a possibilidade de haver um relacionamento homossexual entre as figuras envolvidas. Outros participantes tomam como certo que a personagem preta obstrui a realização do casamento devido à sua provável relação secreta com a noiva. No entanto, na visão da participante $\mathrm{D}$, a pessoa que a personagem preta ama não é necessariamente a noiva, mas também poderia ser o noivo. Como "Xiao Ming" é um nome masculino, podemos inferir que a participante leva em conta o fator homossexual. "O corpo solidificado da noiva ou do noivo" mais uma vez indicia esta visão. Como o participante anterior, ela também parece estar contando uma história, mas não adiciona diálogos para as figuras. "todas as pessoas na igreja ficaram solidificadas em pedra de cor branca" mostra a rica imaginação desta participante, deixando este parágrafo como um conto de fadas.

Excerto 18: A Colgate realiza os sonhos das pessoas." Perguntamos em seguida: "Mas, não foi a Colgate que destruiu o casamento dos noivos?" A participante disse: “...eles não usaram Colgate. A personagem preta realizou o seu sonho porque ele tinha usado a Colgate. A imagem é realmente extraordinária... 
No começo, as ideias da participante D eram dispersas, livres e não sistemáticas. Mais tarde, elas foram unificadas depois de um pensamento cuidadoso. A sua posição também sofreu uma mudança: inicialmente, ela era contra a mercadoria representada pela Colgate, depois, ela mudou de ideia, ressaltando a importância de se escolher um bom produto. É interessante observar que os dois tipos de ponto de vista são completamente opostos, o que revela a contradição, não unidade do sujeito.

Como a participante anterior, ela também parece estar contando uma história, mas não adiciona diálogos para as figuras. $\mathrm{O}$ enunciado "todas as pessoas na igreja ficaram solidificadas em pedra de cor branca" (Excerto 17), na verdade, não atende à lógica e à realidade, pois tem um pouco de magia. Isso traz um estilo parecido ao conto de fadas, manifestado no nível interdiscursivo. Em seguida, a participante D chega a uma conclusão sobre a peça publicitária:

Excerto 19: Eu me sinto muito surpresa ao ver a imagem especial: a propaganda da Colgate é tão criativa! Acho que a imagem principalmente quer mostrar a importância de um bom produto para a vida e o trabalho de uma pessoa.

O enunciado "a propaganda da Colgate é tão criativa!" parece estar associado à questão da transposição da realidade, muito presente no gênero textual dos contos de fadas, estilo esse atribuído à imagem pela participante (Excerto 17). Vemos aqui o processo de construção de sentidos ligado ao efeito interdiscursivo.

Há muitas outras interpretações dos quatro participantes acima que, por limites de espaço, não puderam ser apresentadas aqui. Por isso, na tabela abaixo, vamos apresentálas de forma resumida para que possamos oferecer ao leitor um panorama mais completo dos nossos dados. As interpretações discutidas na seção 4 também estão incluídas nesse panorama apresentado a seguir. A tabela é apresentada da seguinte maneira: nas linhas, apresentamos cada participante (A, B, C e D) e o número de versões distintas que ele/ela produziu durante a atividade de leitura da peça publicitária. Nas colunas, apresentamos as interpretações de cada participante referente ao local onde se passa o evento, à interpretação que o participante dá à cada personagem, ao evento que se passa no local, à ação da personagem preta, à razão da cena ser quase toda branca, ao efeito produzido pela propaganda (ou seja, a atitude do participante em relação ao creme dental), ao gênero discursivo da imagem (se o participante considera a imagem uma peça publicitária), à sua própria posição em relação à peça publicitária em geral e à ideia central desta. 
Tabela 2 - Semelhanças e diferenças dos textos produzidos pelos participantes

\begin{tabular}{|c|c|c|c|c|c|c|c|c|c|}
\hline & & 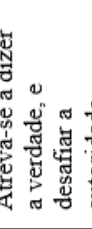 & & 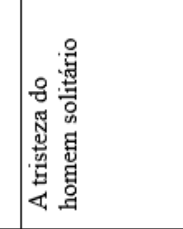 & 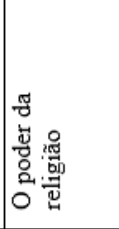 & 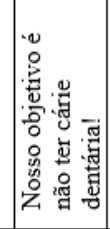 & 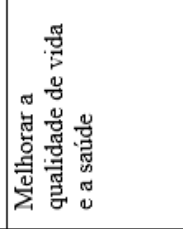 & 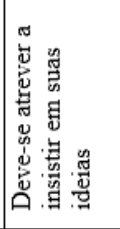 & 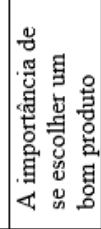 \\
\hline & & 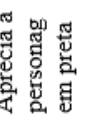 & - & 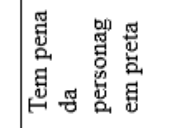 & 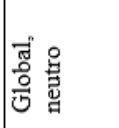 & 总 & 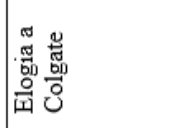 & 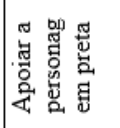 & \\
\hline & & & & 湂 & 䍃 & 淟 & - & 䝿 & \\
\hline & & 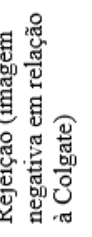 & - & - & - & & 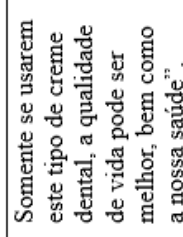 & 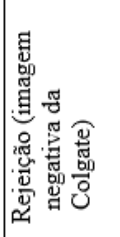 & 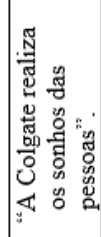 \\
\hline & & & & 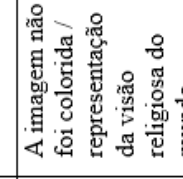 & 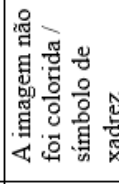 & 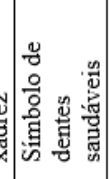 & & 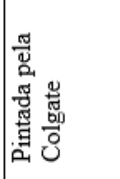 & \\
\hline & & 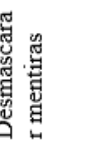 & \begin{tabular}{|l}
$\frac{8}{9}$ \\
高 \\
覀
\end{tabular} & 暿 & 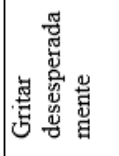 & 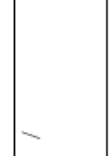 & 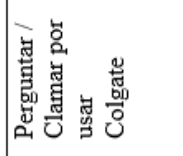 & 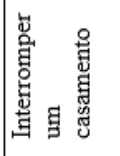 & \\
\hline & & 㼵 & 㬅 & 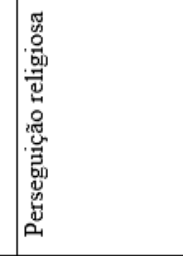 & 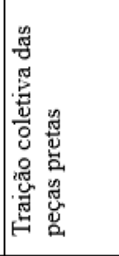 & & 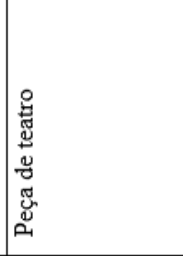 & & \\
\hline & & 邆 & & L & - & - & L & 总焉 & \\
\hline & & 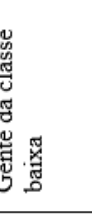 & 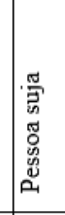 & 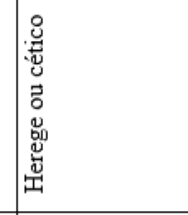 & 递 & 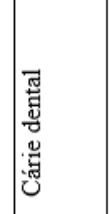 & 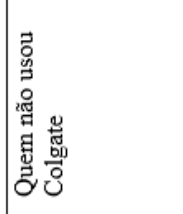 & 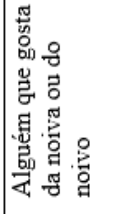 & 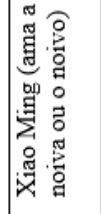 \\
\hline & & 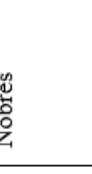 & 8 & 这 & 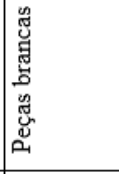 & 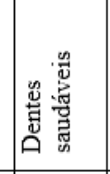 & 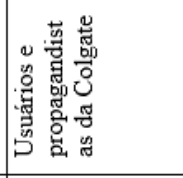 & - & \\
\hline & & 㺃 & & 营 & 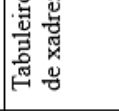 & 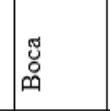 & 总 & 总 & \\
\hline & & 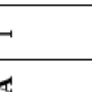 & N & -7 & N & m & o & - & N \\
\hline
\end{tabular}


Em geral, as leituras feitas pelos quatro participantes possuem pontos semelhantes e distintos. Cada participante possui suas próprias histórias de vida e, por isso, aciona diferentes elementos presentes em sua memória discursiva para a interpretação da peça publicitária.

Abaixo enumeramos algumas semelhanças e diferenças entre as leituras dos quatro participantes:

1. O primeiro é a descrição do local na imagem. Dois participantes (A e D) consideram o local uma igreja. A participante $\mathrm{C}$ o vê como um teatro e o participante $\mathrm{B}$ vê o local como um símbolo do tabuleiro de xadrez e uma boca.

2. Relativamente à razão pela qual a imagem é toda branca, a explicação da participante A é que a imagem foi pintada pela pasta de dentes (da Colgate); o participante B supõe que o autor da imagem esqueceu de colocar cores, enquanto $\mathrm{C}$ pensa que é o efeito da luz.

3. A participante $\mathrm{D}$ notou que a imagem é uma propaganda à primeira vista; o participante $\mathrm{B}$ ficou ciente disso à medida que a entrevista avançava; a participante $\mathrm{A}$ não pensou nisso até o final da entrevista; e a participante $C$ não afirmou claramente o gênero discursivo. Portanto, nem todos os participantes consideraram o texto um anúncio publicitário.

4. Também são diversificadas as posições defendidas pelos participantes e a ideia central obtida na interpretação do texto: a participante A aprecia muito o espírito da personagem preta de atrever-se a dizer a verdade e desafiar a autoridade; já a participante D colocase na posição da personagem preta, pensando que uma pessoa deve se atrever a insistir em suas ideias.

5. A leitura da A está mais ligada à religião. E através dos enunciados "a hipocrisia da religião" (Excerto 1) e " A igreja é um local sagrado de peregrinação" (Excerto 2), podemos confirmar que a participante trata a religião como algo negativo no primeiro momento e negativo, no segundo. Em comparação, a figura preta tem uma imagem revolucionária na primeira interpretação de $\mathrm{A}$, enquanto a mesma personagem tem uma imagem depreciável na segunda interpretação da participante.

6. Embora a maioria dos participantes interprete a imagem como um evento religioso (sendo realizado em uma igreja), apenas a participante $\mathrm{D}$ interpreta o evento como um casamento. Essa participante, além de dar à figura preta um nome específico, também leva em conta a possibilidade da homossexualidade, conforme diz no Excerto 17 "Xiao Ming interrompeu uma cerimônia de casamento de um casal realizada na igreja, porque ele não concordava com isso, não importando se ele amava aquele homem ou a mulher".

Pudemos observar, ao longo deste artigo, que perante um mesmo texto, diferentes sujeitos podem ter diferentes pontos de vista. Por exemplo, quanto à descrição do lugar, a maioria dos participantes pensam que é uma igreja, enquanto algumas pessoas acreditam que é um tabuleiro de xadrez, um teatro. E eles também possuem diferentes compreensões sobre as personagens e o evento mostrado na imagem. Podemos facilmente compreender a razão deste resultado: cada participante estabeleceu ligações relevantes entre o texto e os seus conhecimentos prévios e experiências pessoais. Diferentes leitores possuem diferentes domínios de conhecimento, experiências e ideologias, tudo isso compõe as suas memórias discursivas. Portanto, o tipo de inferência elaborado por eles frente a um mesmo texto pode variar por conta dos seus arcabouços socioculturais. 
Para além disso, um mesmo sujeito pode também realizar diferentes leituras em diferentes momentos. Vemos que, com exceção da participante $\mathrm{C}$, todos os outros participantes forneceram mais de uma versão de leitura. Assim, podemos considerar que o pensamento humano não é linear, mas sim divergente, pelo que as leituras de um mesmo participante podem ser diversificadas. Além disso, essas leituras expressam ideias até mesmo opostas nas suas versões distintas, em que a identidade das personagens na imagem também são alteradas. Isso mostra a heterogeneidade do discurso e a sua opacidade, pois não é uniforme, mas formado pelos sentidos divergentes em direções diferentes, por vezes até mesmo contraditórias.

Vale refletirmos, portanto, como trabalhar com leitura em nossas vidas. Uma vez que a leitura não é um processo linear, de certo ou errado, de verdadeiro ou falso, mas sim um bólide de sentidos que se desintegra e se reconstrói no momento em que interagimos com o texto, como podemos quebrar com as concepções tradicionais para explorarmos a leitura de maneira mais satisfatória nos diferentes contextos em que ela está inserida (escola, trabalho, relações sociais etc)? Embora este trabalho não possa responder a essas indagações, acreditamos ter colaborado para uma visão mais abrangente do complexo processo de ler e de produzir sentidos.

\section{REFERÊNCIAS}

BAKHTIN, M. Estética da criação verbal. Tradução Paulo Bezerra. 4. ed. São Paulo: Martins Fontes. 2003.

CAZARIN, E. A. A leitura: uma prática discursiva. Linguagem em (Dis)curso, v. 6, n. 2, p. 299-313, 2006.

CORACINI, M. J. Leitura: decodificação, processo discursivo...? In: CORACINI, M. J. (Org.). O jogo discursivo na aula de leitura. Campinas: Pontes, 1995. p. 13-20.

FIORIN, J. L. Interdiscursividade e intertextualidade. In: BRAIT, B. (Org.). Bakhtin: outros conceitoschave. São Paulo: Contexto, 2006. p. 161-194.

LEFFA, V. Aspectos da Leitura. Porto Alegre: Sagra - D. C. Luzzatto Editores, 1996.

MARTINS, M. O que é leitura? São Paulo: Editora Brasiliense. 2003.

ORLANDI, E. P. Análise de Discurso: princípios \& procedimentos. Campinas: Pontes, 2005.

Interpretação: autoria, leitura e efeitos do trabalho simbólico. 2. ed. Rio de Janeiro: Vozes. 1998. 1992. Língua e conhecimento linguístico: para uma histórias das ideias no Brasil. São Paulo: Cortez.

Terra à vista! Discurso do confronto: velho e novo mundo. São Paulo: Cortez, 1990.

A linguagem e seu funcionamento: as formas do discurso. Campinas: Pontes, 1987.

PÊCHEUX, M. O discurso: estrutura ou acontecimento. Tradução Eni Pulcinelli Orlandi. Campinas: Pontes, 1990.

PRÊMIO DE PRATA (categoria mídia impressa - Festival de Publicidade de Cannes). Disponível em: <http://www.coloribus.com/adsarchive/prints/colgate-toothpaste-church-14498805/>. Acesso: 15 jan. 2014.

SHAN, He; MOUTINHO, Ricardo. Deslizando sentidos: uma análise das interpretações de leitores chineses para uma peça publicitária veiculada na mídia impressa latino-americana. Linguagem em (Dis)curso - LemD, Tubarão, SC, v. 16, n. 1, p. 57-77, jan./abr. 2016. 
Recebido em: 02/08/15. Aprovado em: 18/01/16.

Title: The sliding of meanings: analyzing the interpretations produced by chinese readers on an advertisement published in latin american print media

Authors: He Shan; Ricardo Moutinho

Abstract: This study investigates the meanings produced by Chinese participants based on their interpretation of an advertisement by Colgate company divulgated on South American print media and holder of the Silver Award at Cannes Lions 2011 Festival. According to the discursive perspective, we consider the text as a 'bolide of meanings', connected to its exteriority, namely the interdiscourse. For this reason, text is not a single closed unity, nor something with an evident or preconceived meaning to be captured by its reader. Based on this idea, different accounts from a same text are possible. In order to support this hypothesis, we carried out some interviews with semi-structured topics with four participants and analyzed their interpretations on the abovementioned advertisement, identifying the similarities and differences among them. The results show that participants produced different accounts, which identify them not only as subjects of a different culture from the one in which the advertisement was previously divulgated, but as different subjects among themselves, since interpretation is not a linear move. Rather, it is part of a complex interdiscursive game.

Keywords: Reading. Advertisement. Chinese participants.

Título: Deslizando sentidos: un análisis de interpretaciones de lectores chinos para una pieza publicitaria difundida en medios de comunicación impresos latinoamericanos

Autores: He Shan; Ricardo Moutinho

Resumen: En este trabajo hemos investigado los efectos producidos por sujetos chinos desde la lectura de una pieza publicitaria de la marca Colgate, difundida en los medios de comunicación impresos sudamericanos, vencedora del Premio de Plata en el Festival de Cannes de 2011. De acuerdo con la perspectiva discursiva, consideramos el texto un conjunto de sentidos, ligado con su exterioridad, es decir, el interdiscurso. El texto no es una unidad encerrada en sí mismo, ni algo que tiene un sentido evidente y listo para ser capturado por el sujeto-lector. De esa manera, distintas lecturas desde un mismo texto son posibles. Para sostener esta hipótesis, realizamos una serie de entrevistas con tópicos semiestructurados con cuatro participantes, y analizamos el corpus constituido por sus lecturas relacionadas con esa pieza, identificando las semejanzas y diferencias entre ellas. Los resultados muestran que los participantes han producido lecturas diversificadas, que los identifican no solo como sujetos pertenecientes a una cultura diferente de aquella en la cual la pieza fue inicialmente divulgada, pero como sujetos diferentes entre ellos, una vez que la interpretación de un texto no es linear, pero marcada por el complejo juego interdiscursivo.

Palabras-clave: Lectura. Pieza publicitaria. Participantes chinos.

SHAN, He; MOUTINHO, Ricardo. Deslizando sentidos: uma análise das interpretações de leitores chineses para uma peça publicitária veiculada na mídia impressa latino-americana. Linguagem em (Dis)curso - LemD, Tubarão, SC, v. 16, n. 1, p. 57-77, jan./abr. 2016. 